\title{
Association of Functional Genetic Variants of HOTAIR with Hepatocellular Carcinoma (HCC) Susceptibility in a Chinese Population
}

\author{
Hao Lia Xian-Mei Tang ${ }^{b}$ Yangchen Liuc Weizhen Lic Qiaoyun Chen ${ }^{c} \quad$ Yan Pane \\ aDepartment of Clinical Laboratory, The Taixing People's Hospital, Taixing, bepartment of Infectious \\ Diseases, Hanzhong Central Hospital, Hanzhong, 'Department of Radiotherapy, The Taixing People's \\ Hospital, Taixing, dDepartment of Central Laboratory, The Affiliated People's Hospital of Jiangsu \\ University, Zhenjiang, e'Department of Clinical Laboratory, The Lianshui County People's Hospital, \\ Lianshui, China
}

\section{Key Words}

Hepatocellular carcinoma $\bullet$ HOTAIR • Single nucleotide polymorphisms

\begin{abstract}
Background/Aims: The HOX transcript antisense intergenic RNA (HOTAIR), a long noncoding RNA (IncRNA), plays an important role in the pathogenesis and progression of multiple tumors. The aim of the present study was to evaluate whether common single nucleotide polymorphisms (SNPs) in HOTAIR are related to hepatocellular carcinoma (HCC) susceptibility in a Chinese population. Methods: We genotyped three SNPs of HOTAIR in a hepatocellular carcinoma (HCC) case-control study, including 482 cases and 520 control subjects. SNPs were genotyped using real-time polymerase chain reaction (RT-PCR). Associations between gene polymorphisms and HCC were evaluated using multiple logistic regression analysis. The allelespecific effects on HOTAIR expression in HCC were confirmed by real time quantitative PCR and luciferase activity assays. The influence of HOTAIR SNPs on the proliferation of HCC cells was evaluated using a CCK-8 assay. Results: Significant associations were observed between the HOTAIR rs920778 C>T polymorphism and HCC risk (TT versus CC: $\mathrm{OR}=1.634,95 \% \mathrm{CI}=1.028$ $2.598, \mathrm{P}=0.046$ ) and the allelic model (allele $\mathrm{T}$ versus allele $\mathrm{C}$ : $\mathrm{OR}=1.293,95 \% \mathrm{CI}=1.060$ $1.577, P=0.011$ ). However, no statistically significant differences of rs4759314 and rs1899663 genotypes were observed between patients and controls (both $\mathrm{P}>0.05$ ). The increased risk for rs920778 TT genotype carriers was more evident in a sub-group of drinkers (OR $=3.103$, $95 \% \mathrm{CI}=1.151-8.368, p=0.025)$ and in people positive for HBV infection (OR $=2.885,95 \%$ $C I=1.086-7.663, p=0.034) . R T-P C R$ and luciferase activity assay confirmed that the rs920778 TT genotype induced significantly higher HOTAIR levels than did the CC genotype $(P<0.05)$. CCK- 8 assays and colony formation assays demonstrated that the rs920778 TT genotype had $\mathrm{H}$. Li and X. Tang contributed equally to this work.

\begin{tabular}{ll}
\hline Yan Pan & $\begin{array}{l}\text { Department of Clinical Laboratory, The Lianshui County People's Hospital, } \\
\text { Lianshui, (China) }\end{array}$
\end{tabular}




\section{Cellular Physiology Cell Physiol Biochem 2017;44:447-454 \begin{tabular}{l|l} 
DOI: 10.1159/000485011 & $\begin{array}{l}\text { O 2017 The Author(s). Published by S. Karger AG, Basel } \\
\text { www.karger.com/cpb }\end{array}$ \\
\hline
\end{tabular} \\ Li et al.:HOTAIR SNP and Hepatocellular Carcinoma}

a higher proliferation rate of HCC cells than did the CC genotype $(P<0.05)$. Conclusion: These results suggest that SNP rs920778 of HOTAIR acts as a potential biomarker for predicting hepatocellular carcinoma, and further studies are warranted to confirm these findings.

\section{Introduction}

Hepatocellular carcinoma (HCC) is one of the most common cancers and is commonly referred to as 'the king of cancer' [1]. The latest data indicate that approximately half the new cases of HCC were reported in China [2]. Previous studies showed that HCC is a complex disease that is associated with various risk factors and cofactors [3]. For example, hepatitis $\mathrm{B} / \mathrm{C}$ virus (HBV) infection, excessive alcohol intake and nutrition deficiency were found associated with the occurrence of HCC [4]. Despite the remarkable advances in epidemiology, the real cause of HCC remains unclear. Many studies reported that not all subjects exposed to the same environmental conditions and lifestyle risk factors develop HCC [5]. Therefore, genetic factors may play an important role in the carcinogenesis of HCC.

Long non-coding RNAs (lncRNAs) are a class of non-coding transcripts that are longer than 200 nucleotides. Increasing evidence demonstrated that lncRNAs are involved in the occurrence of tumors due to their function as oncogenes or tumor suppressors [6, 7]. Studies also suggested that single nucleotide polymorphisms (SNPs) in lncRNAs may modulate gene expression and function, leading to effects on their interacting partners $[8,9]$. Thus, the association between SNPs in lncRNAs with the risk of cancers was investigated in the last several decades [10-12]. For example, Wang et al. reported that three SNPs in ZNRD1-AS1 are all associated with cancer risk in an Asian population [13]. Verhaegh et al. identified a SNP polymorphism in the lncRNA H19 gene that is associated with the risk of non-muscleinvasive bladder cancer [14]. Collectively, these findings indicated that SNPs in lncRNAs may play important roles in tumorigenesis and may be a useful biomarker for the early diagnosis of tumors.

The IncRNA HOX transcript antisense intergenic RNA (HOTAIR), which is encoded by the homeobox $C$ gene $(H O X C)$, was previously identified to participate in the occurrence and progression of multiple malignances $[15,16]$. Gupta et al. initially reported that HOTAIR expression was increased in breast cancer tissues, as well as being related to a poor prognosis of breast cancer progression [17]. Recently, increasing numbers of studies investigated the association between single nucleotide polymorphisms in the HOTAIR locus with cancer risk [18]. However, the results of these studies were inconsistent. To date, little is known regarding the mechanisms by which HOTAIR SNPs are involved in the development of HCC. Thus, we genotyped three HOTAIR SNPs in a case-control study to explore the association between HOTAIR genotypes and HCC risk.

\section{Materials and Methods}

\section{Ethics statement}

This study was approved by the Ethics Committee of Hanzhong Central Hospital, and written informed consent was obtained from each participant.

\section{Patients}

From January 2013 to October 2016, for the HCC case group, we recruited 482 patients (mean age of $55.6 \pm 12.3$ years, of which 334 cases were male and 148 were female) at Hanzhong Central Hospital. During the same period, 520 individuals (mean age of $53.8 \pm 13.1$ years, with 372 males and 148 females) were enrolled in the present study as the control group. All patients were confirmed by at least two pathologists. Patients and normal controls were excluded from this study if they had any history of other cancers. General characteristics, such as gender, age, cigarette smoking, alcohol consumption, hepatitis virus infection and HCC family history, were collected by querying medical records. 


\section{Cellular Physiology Cell Physiol Biochem 2017;44:447-454 \\ \begin{tabular}{ll|l} 
and Biochemistry Published online: November 15, 2017 & $\begin{array}{l}\text { (c) } 2017 \text { The Author(s). Published by S. Karger AG, Basel } \\
\text { www.karger.com/cpb }\end{array}$
\end{tabular}}

Li et al.:HOTAIR SNP and Hepatocellular Carcinoma

\section{DNA extraction}

A total of $5 \mathrm{ml}$ intravenous whole blood collected from HCC patients and controls was placed in tubes containing EDTA. The genomic DNA was extracted using a Blood Genome DNA Extraction Kit (TAKARA, Dalian, China) according to the manufacturer's instructions. DNA was dissolved in Tris-EDTA (TE) buffer for the polymerase chain reactions.

\section{HOTAIR SNP genotyping}

Based on published association studies, three HOTAIR HapMap tagSNPs (htSNP) (rs1899663, rs920778, and rs4759314) were selected and genotyped as described previously [19]. SNP genotyping was performed without knowledge of the patient or control status. To ensure the accuracy of genotyping, 10\% random sample was subjected to DNA sequencing, and the reproducibility was $100 \%$.

\section{Real-time analyses of IncRNA HOTAIR}

Total RNA was isolated from HCC tissues or cells using TRIzol Reagent (Invitrogen, Carlsbad, CA, USA) and dissolved in RNase-Free water according to the manufacturer's recommended protocol. RNA from each sample was reverse transcribed into cDNA using a cDNA Synthesis Kit (TAKARA, Dalian, China). The expression of HOTAIR was calculated relative to the expression of GAPDH mRNA using the $2^{-\Delta \Delta C t}$ method as described previously [20]. All qPCRs were performed using the BIO-RAD CFX-96 real-time PCR system in triplicate. Primer sequences were as follows: human HOTAIR, F-5'-ACGAAGGTGAAAGCGAACCA-3', R-5'-TTCATGTGGCGAGCTAGGAC-3'; and human GAPDH, F-5'- TGCACCACCAACTGCTTAGC-3', R-5'GGCATGGACTGTGGTCATGAG-3.

\section{Cell proliferation assay}

The assay was performed as described previously [21]. Briefly, approximately $5 \times 10^{3}$ cells transfected with HOTAIR-CC expression construct or HOTAIR-TT expression construct were plated in 96-well plates. The proliferation rate was assessed using a CCK-8 Kit (Beyotime, Haimen, China) at the time points 0, 24, 48 , and $72 \mathrm{~h}$. The absorbance was measured at $570 \mathrm{~nm}$ using a spectrophotometer (Thermo, Multiskan FC).

\section{Colony formation assays}

HCC cells were harvested $24 \mathrm{~h}$ after transfection with the HOTAIR-CC expression construct or HOTAIRTT expression construct and were then seeded into a 6-well cell culture plate (200 cells/well). After 14 days, cells were fixed with methanol and stained with $1 \%$ crystal violet (Sigma, USA).

\section{Dual luciferase reporter assay}

The fragment including the rs920778C of HOTAIR was directly synthesized by the Shinegene Company (Shanghai, China) and cloned into the pGL3-basic plasmid yielding the wild-type vector (pGL3-HOTAIRWT). The mutation fragment of HOTAIR (pGL3-HOTAIR-MUT) was generated by site-specific mutagenesis at the rs920778 site (C>T). The reporter gene constructs pGL3-Basic, pGL3-HOTAIR-WT, or pGL3-HOTAIRMUT, as well as pRL-SV40, were co-transfected into HEK293 cells. After 48 h, the luciferase activity of firefly and Renilla were measured using the Dual Luciferase assay system (Promega) following the manufacturer's instructions. All experiments were independently performed in triplicate.

\section{Statistics}

A goodness-of-fit $\chi^{2}$ test was used to test the Hardy-Weinberg equilibrium (HWE). The differences in demographic variables and genotype distributions of HOTAIR htSNPs between HCC cases and controls was tested by Pearson's $\chi 2$ test. The associations between HOTAIR genotypes and the risk of HCC were estimated by odds ratio (OR) and their 95\% confidence intervals (CIs), as computed using the unconditional logistic regression model. All ORs were adjusted for age, sex, hepatitis virus infection, cigarette smoking and alcohol consumption. A $P$-value $<0.05$ was considered the criterion of statistical significance. All statistical analyses were two-sided and performed with the SPSS version 12.0 for Windows statistical software (SPSS Inc., Chicago, IL, USA). 


\section{Cellular Physiology Cell Physiol Biochem 2017;44:447-454 \begin{tabular}{ll|l} 
and Biochemistry Published onIIne: November 15, 2017 & $\begin{array}{l}\text { C } 2017 \text { The Author(s). Published by S. Karger AG, Basel } \\
\text { www.karger.com/cpb }\end{array}$
\end{tabular}

\section{Results}

Demographic characteristics of cases and controls

The distribution of demographic characteristics of this study are presented in Table 1. There were no significant differences in the age and gender distribution, and smoking and HCC family history, between HCC patients and controls $(P>$ $0.05)$. However, there were more drinkers and HbsAg (+) individuals in the HCC patient group $(P<0.05)$.

\section{Associations of HOTAIR} SNPs with HCC risk

Genotype distributions of the three selected HOTAIR SNPs in HCC cases and controls are summarized in Table 2. The genotype distributions of the three SNPs among both the patient and control groups were in HWE (Table 2), suggesting that the cases and controls used in this study were selected randomly from the population. The results from logistic regressive analyses are shown in Table 3. Significant associations were observed between the HOTAIR rs920778 C>T polymorphism and HCC risk under a homozygote comparison model (TT versus CC: OR = $1.634,95 \% \mathrm{CI}=1.028-2.598, P=0.046)$ and the allelic model (allele T versus allele C: OR $=1.293,95 \% \mathrm{CI}=1.060-1.577$, $\mathrm{P}=0.011$ ). However, no statistically significant differences for rs4759314 and rs1899663 genotypes were observed between patients and controls (both $P>0.05$ ). As a result, the present study did not perform further investigation of these two genetic variants.

\section{Stratification} analysis

To assess the risk of rs920778 to HCC, a stratified analysis was performed by subgroups of age, sex, smoking, al-
Table 1. Demographic information of cases and controls

\begin{tabular}{llll}
\hline Characteristics & Controls (n=520) (\%) & Cases (n=482) (\%) & $P$ \\
\hline Age & & & 0.798 \\
$\geq 55$ years & $298(57.3)$ & $281(58.3)$ & \\
$<55$ years & $222(42.7)$ & $201(41.7)$ & \\
Gender & & & 0.447 \\
$\quad$ Male & $372(71.5)$ & $334(69.3)$ & \\
$\quad$ Female & $148(28.5)$ & $148(30.7)$ & 0.143 \\
Smoking & & & \\
$\quad$ Never & 306 & 261 & 0.048 \\
$\quad$ Ever & 214 & 221 & \\
Alcohol Consumption & & & \\
$\quad$ Never & $418(80.4)$ & $362(75.1)$ & \\
$\quad$ Ever & $102(19.6)$ & $120(24.9)$ & \\
HBV infection & & & \\
$\quad$ HbsAg (-) & $429(82.5)$ & $156(32.4)$ & \\
$\quad$ HbsAg (+) & $91(17.5)$ & $326(67.6)$ & \\
HCC family history & & $47(9.8)$ & \\
$\quad$ Yes & $43(8.3)$ & $435(90.2)$ & \\
No & $477(91.7)$ & &
\end{tabular}

Table 2. The Weinberg equilibrium (HWE) in the present study

\begin{tabular}{llll}
\hline SNP & & $X^{2}$ & $P$ \\
\hline rs920778 & Controls & 1.707 & 0.191 \\
& Cases & 2.209 & 0.137 \\
rs1899663 & Controls & 0.406 & 0.524 \\
& Cases & 0.177 & 0.674 \\
rs4759314 & Controls & 0.015 & 0.900 \\
& Cases & 0.294 & 0.587 \\
\hline
\end{tabular}

Table 3. Associations between selected SNPs in HOTAIR and HCC risk

\begin{tabular}{|c|c|c|c|c|c|c|}
\hline Genotype & Controls $(n=520)(\%)$ & Cases $(n=482)(\%)$ & $x^{2}$ & $P$ & OR $(95 \% \mathrm{CI})$ & $\mathrm{P}$ \\
\hline \multicolumn{7}{|l|}{ rs920778 } \\
\hline $\mathrm{CC}$ & $304(58.5)$ & $248(51.5)$ & \multirow{5}{*}{6.601} & \multirow{5}{*}{0.048} & & \\
\hline CT & $180(34.6)$ & $186(38.6)$ & & & $1.271(0.969-1.652)$ & 0.093 \\
\hline TT & $36(6.9)$ & $48(10.0)$ & & & $1.635(1.024-2.602)$ & 0.047 \\
\hline $\mathrm{C}$ allelic & $788(75.8)$ & $682(70.7)$ & & & & \\
\hline $\mathrm{T}$ allelic & $252(24.2)$ & $282(29.3)$ & & & $1.297(1.055-1.579)$ & 0.013 \\
\hline \multicolumn{7}{|l|}{ rs1899663 } \\
\hline GG & $367(70.6)$ & $334(69.3)$ & & & & \\
\hline GT & $142(27.3)$ & $136(28.2)$ & & & $1.048(0.793-1.392)$ & 0.721 \\
\hline $\mathrm{TT}$ & $11(2.1)$ & $12(2.5)$ & 0.286 & 0.867 & $1.197(0.524-2.759)$ & 0.681 \\
\hline G allelic & $876(84.2)$ & $804(83.4)$ & & & & \\
\hline $\mathrm{T}$ allelic & $164(15.8)$ & $160(16.6)$ & & & $1.065(0.834-1.349)$ & 0.633 \\
\hline \multicolumn{7}{|l|}{ rs4759314 } \\
\hline AA & $356(68.5)$ & $315(65.4)$ & & & & \\
\hline AG & 149 (28.7) & $147(30.5)$ & & & $1.118(0.845-1.469)$ & 0.444 \\
\hline GG & $15(2.9)$ & $20(4.1)$ & 1.794 & 0.408 & $1.508(0.755-2.997)$ & 0.295 \\
\hline A allelic & $861(82.7)$ & 777 (80.6) & & & & \\
\hline G allelic & $179(17.2)$ & $187(19.4)$ & & & $1.159(0.925-1.451)$ & 0.227 \\
\hline
\end{tabular}


cohol consumption, HBV infection status, and HCC family history (Table 4). The increased risk for rs920778 TT genotype carriers was more evident in a sub-group of drinkers (OR = 3.103, 95\% CI $=1.151-8.368$, $\mathrm{p}=0.025$ ) and positive HBV infection $(\mathrm{OR}=2.885,95 \% \mathrm{CI}=$ 1.086-7.663, $\mathrm{p}=0.034$ ) (under the homozygote comparison model), suggesting that the risk of HCC was enhanced by the potential interactions between rs920778 and alcohol consumption and HBV infection.

\section{Associations of HOTAIR SNP rs920778 with HOTAIR expression}

Subjects with the rs920778 TT genotype had significantly higher HOTAIR levels than those with the CC genotypes in HCC tissues (Fig. 1A, P $<0.05$ ). Next, we investigated the SNP rs920778 regulatory potential in HCC using reporter gene assays (Fig. 1B). HEK293 cells transfected with the HOTAIR rs920778T allelic reporter plasmid (pGL3-HOTAIRMUT) showed significantly elevated luciferase activities compared to cells transfected with the rs920778C allelic reporter plasmid (pGL3-HOTAIRWT) $(\mathrm{P}<0.05)$.

\section{Effects of HOTAIR rs 920778} on HCC cells proliferation

To determine the underlying mechanism by which the rs920778 $\mathrm{T}$ allele confers an increased risk of HCC, we also performed a cell proliferation assay to test the effect of rs920778 on HCC cell proliferation. The CCK-8 assay showed a higher proliferation rate of HCC LM3 cells transfected with the rs $920778 \mathrm{~T}$ allele than with the $\mathrm{C}$ allele (Fig. 2A). Consistent with the cell viability assays, HCC LM3 cells transfected with the rs920778 $\mathrm{T}$ allele have a higher colony formation rate than HCC LM3 cells transfected with the rs920778 C allele (Fig. 2B, 2C).

Table 4. Stratification analysis for associations between rs920778 and HCC risk

\begin{tabular}{|c|c|c|c|c|c|}
\hline Variable & Genotype & $\begin{array}{l}\text { Control } \\
\mathrm{N}\end{array}$ & $\begin{array}{l}\text { Case } \\
\mathrm{N}\end{array}$ & OR $(95 \% \mathrm{CI})$ & $P$ \\
\hline \multicolumn{6}{|l|}{ Age } \\
\hline \multirow[t]{3}{*}{$\geq 55$ years } & $\mathrm{CC}$ & 176 & 147 & & \\
\hline & $\mathrm{CT}$ & 101 & 104 & $1.233(0.868-1.751)$ & 0.247 \\
\hline & $\mathrm{TT}$ & 21 & 30 & $1.710(0.940-3.114)$ & 0.097 \\
\hline \multirow[t]{3}{*}{$<55$ years } & $\mathrm{CC}$ & 128 & 101 & & \\
\hline & $\mathrm{CT}$ & 79 & 82 & $1.315(0.878-1.971)$ & 0.216 \\
\hline & $\mathrm{TT}$ & 15 & 18 & $1.521(0.731-3.166)$ & 0.269 \\
\hline \multicolumn{6}{|l|}{ Gender } \\
\hline \multirow[t]{3}{*}{ Male } & $\mathrm{CC}$ & 218 & 172 & & \\
\hline & $\mathrm{CT}$ & 129 & 129 & $1.267(0.925-1.738)$ & 0.148 \\
\hline & $\mathrm{TT}$ & 25 & 33 & $1.673(0.959-2.920)$ & 0.089 \\
\hline \multirow[t]{3}{*}{ Female } & $\mathrm{CC}$ & 86 & 76 & & \\
\hline & $\mathrm{CT}$ & 51 & 57 & $1.265(0.777-2.060)$ & 0.385 \\
\hline & $\mathrm{TT}$ & 11 & 15 & $1.543(0.668-3.564)$ & 0.398 \\
\hline \multicolumn{6}{|l|}{ Smoking } \\
\hline \multirow[t]{3}{*}{ Never } & $\mathrm{CC}$ & 179 & 134 & & \\
\hline & $\mathrm{CT}$ & 106 & 101 & $1.273(0.895-1.811)$ & 0.208 \\
\hline & $\mathrm{TT}$ & 21 & 26 & $1.654(0.892-3.066)$ & 0.117 \\
\hline \multirow[t]{3}{*}{ Ever } & $\mathrm{CC}$ & 125 & 114 & & \\
\hline & $\mathrm{CT}$ & 74 & 85 & & \\
\hline & $\mathrm{TT}$ & 15 & 22 & $1.608(0.796-3.250)$ & 0.217 \\
\hline \multicolumn{6}{|c|}{ Alcohol Consumption } \\
\hline \multirow[t]{3}{*}{ Never } & $\mathrm{CC}$ & 244 & 190 & & \\
\hline & $\mathrm{CT}$ & 144 & 142 & $1.266(0.939-1.709)$ & 0.127 \\
\hline & $\mathrm{TT}$ & 30 & 30 & $1.284(0.748-2.205)$ & 0.407 \\
\hline \multirow[t]{3}{*}{ Ever } & $\mathrm{CC}$ & 60 & 58 & & \\
\hline & $\mathrm{CT}$ & 36 & 44 & $1.264(0.715-2.235)$ & 0.470 \\
\hline & $\mathrm{TT}$ & 6 & 18 & $3.103(1.151-8.368)$ & 0.025 \\
\hline \multicolumn{6}{|l|}{ HBV infection } \\
\hline \multirow[t]{3}{*}{$\operatorname{HbsAg}(-)$} & $\mathrm{CC}$ & 251 & 90 & & \\
\hline & $\mathrm{CT}$ & 147 & 61 & $1.157(0.789-1.698)$ & 0.491 \\
\hline & $\mathrm{TT}$ & 31 & 5 & $0.450(0.170-1.192)$ & 0.110 \\
\hline \multirow[t]{3}{*}{ HbsAg $(+)$} & $\mathrm{CC}$ & 53 & 158 & & \\
\hline & $\mathrm{CT}$ & 33 & 125 & $1.271(0.775-2.082)$ & 0.384 \\
\hline & $\mathrm{TT}$ & 5 & 43 & $2.885(1.086-7.663)$ & 0.034 \\
\hline \multicolumn{6}{|c|}{ HCC family history } \\
\hline \multirow[t]{3}{*}{ Yes } & $\mathrm{CC}$ & 25 & 24 & & \\
\hline & $\mathrm{CT}$ & 15 & 18 & $1.250(0.516-3.029)$ & 0.658 \\
\hline & $\mathrm{TT}$ & 3 & 5 & $1.736(0.373-8.074)$ & 0.706 \\
\hline \multirow[t]{3}{*}{ No } & $\mathrm{CC}$ & 279 & 224 & & \\
\hline & $\mathrm{CT}$ & 165 & 168 & $1.268(0.961-1.674)$ & 0.104 \\
\hline & $\mathrm{TT}$ & 33 & 43 & $1.623(0.998-2.640)$ & 0.064 \\
\hline
\end{tabular}




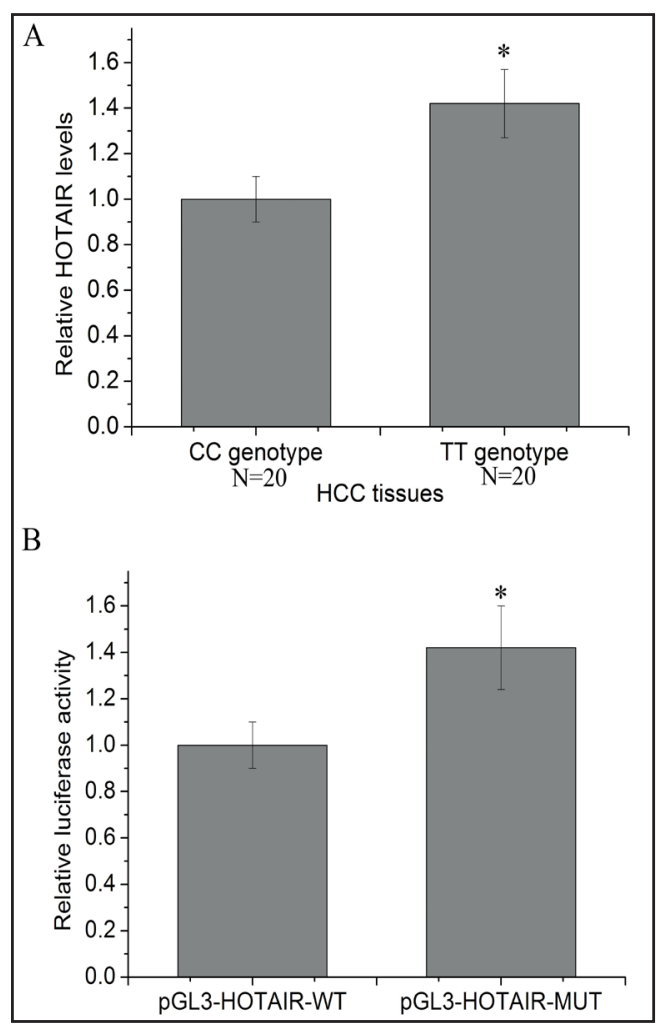

Fig. 1. Associations of the HOTAIR SNP rs 920778 with HOTAIR expression. A: The expression of HOTAIR in different genotype HCC tissues was measured by RT-PCR. B: The luciferase activity was detected in HEK293 cells transfected with pGL3-HOTAIR-MUT or pGL3-HOTAIR-WT. $* \mathrm{P}<0.05$.

\section{Discussion}

In the present study, through a case-control study, we investigated the role of lncRNA HOTAIR in HCC and the association between HOTAIR SNPs and HCC susceptibility. To the best of our knowledge, this study is the first to report that rs920778 in HOTAIR had a strong association with the risk of HCC in a Chinese population. We observed that the rs920778 SNP in the HOTAIR gene modulates lncRNA HOTAIR expression, which is consistent with the findings of previous reports.

Homeobox transcript antisense intergenic RNA (HOTAIR) is one type of IncRNA, which has 2,158 bases and is localized on chromosome within the homeobox C (HOXC) gene cluster [22]. Recently, many studies showed that HOTAIR is overexpressed in a variety of tumors, including breast cancer, colon cancer and liver cancer, and plays important roles in cancer pathogenesis $[23,24]$. Lv et al. reported that the expression levels of HOTAIR correlated clinically with esophageal squamous cell carcinoma (ESCC) progression [25]. Moreover, HOTAIR plays an important role in the malignant phenotype of ESCC cells through its modulation of diverse biological processes, including proliferation, migration and invasion. Furthermore, HOTAIR overexpression was associated with lymph node metastasis in many tumors [26]. However, the functional impact of HOTAIR in HCC is far from fully elucidated, and other epigenetic effects of HOTAIR are unclear. In the present study, we observed that a SNP polymorphism in the lncRNA HOTAIR gene may be associated with the occurrence of HCC in a Chinese population. 


\section{Cellular Physiology Cell Physiol Biochem 2017;44:447-454 \begin{tabular}{l|l|l} 
and Biochemistry 10.1159/000485011 & $\begin{array}{l}\text { C } 2017 \text { The Author(s). Published by S. Karger AG, Basel } \\
\text { www.karger.com/cpb }\end{array}$
\end{tabular} \\ Li et al.:HOTAIR SNP and Hepatocellular Carcinoma}

Studies have also demonstrated that genetic variants in lncRNAs may influence the splicing and stability of their target messenger RNA (mRNA) conformation, leading to dysfunction of their interacting partners $[8,9]$. Thus, the association of polymorphisms in IncRNAs with the risk of cancers has attracted considerable interest $[10,21]$. The relationships of HOTAIR polymorphisms, including rs4759314 and rs920778, with sensitivities to cancers were investigated among several ethnicities [27]. However, the results of these studies are inconsistent. For example, a previous study report that the $\mathrm{T}$ allele of rs12826786 increased the risk of developing adenocarcinoma of the gastric cardia in a Chinese population [28]; however, among the Turkish population, researchers found that the same variant (HOTAIR rs12826786 C>T polymorphism) was not associated with genetic susceptibility to gastric cancer [29]. In our study, we found that rs920778 was associated with the development of hepatocellular carcinoma. The function of rs920778 on HOTAIR was confirmed in other cancers, including esophageal squamous cell carcinoma [19], gastric cancer [30], colorectal cancer [21], and breast cancer [31]. Moreover, Zhang et al. reported that SNP rs920778 in HOTAIR may affect the expression of HOTAIR, which may be an underlying mechanism by which the SNP affects tumor susceptibility [20]. In the present study, we confirmed the allelic regulation of rs920778 on IncRNA HOTAIR expression. Furthermore, we found that HCC cells transfected with the rs $920778 \mathrm{~T}$ allele had a higher proliferation rate than that of HCC cells transfected with the CC allele $(\mathrm{P}<0.05)$. Therefore, we propose that rs 920778 may be a regulatory SNP, which regulates the expression of HOTAIR and contributes to the genetic susceptibility and proliferation of hepatocellular carcinoma.

\section{Conclusion}

In summary, we identified a genetic susceptibility SNP IncRNA HOTAIR rs920778 in HCC development in a Chinese population. The rs920778 C > T polymorphism was associated with increased HOTAIR expression, which may be the underlying mechanism influencing HCC susceptibility and proliferation. These data suggest that genetic variants in HOTAIR may act as potential risk factors and may represent targets for HCC therapy in the future.

\section{Disclosure Statement}

The author(s) declared no potential conflicts of interest with respect to the research, authorship, and/or publication of this article.

\section{References}

1 Zhang S, Zheng R, Zeng H, Chen W: [The incidence differences among sex, geographical areas and mean age of diagnosis for liver cancer in China, 1989-2008]. Zhonghua Yu Fang Yi Xue Za Zhi 2014;48:355-360.

$>2$ Liu CJ, Ma XW, Zhang XJ, Shen SQ: pri-miR-34b/c rs4938723 polymorphism is associated with hepatocellular carcinoma risk: a case-control study in a Chinese population. Int J Mol Epidemiol Genet 2017;8:1-7.

-3 Cai J, Cai Y, Ma Q Chang F, Xu L, Zhang G, Guo X: Association of p53 codon 72 polymorphism with susceptibility to hepatocellular carcinoma in a Chinese population from northeast Sichuan. Biomed Rep 2017;6:217-222.

4 Tsochatzis EA, Meyer T, Burroughs AK: Hepatocellular carcinoma. N Engl J Med 2012;366:92;92-93.

-5 Makarova-Rusher OV, Altekruse SF, McNeel TS, Ulahannan S, Duffy AG, Graubard BI, Greten TF and McGlynn KA: Population attributable fractions of risk factors for hepatocellular carcinoma in the United States. Cancer 2016;122:1757-1765.

6 Li L, Feng T, Lian Y, Zhang G, Garen A, Song X: Role of human noncoding RNAs in the control of tumorigenesis. Proc Natl Acad Sci U S A 2009;106:12956-12961.

7 Zhang X, Rice K, Wang Y, Chen W, Zhong Y, Nakayama Y, Zhou Y, Klibanski A: Maternally expressed gene 3 (MEG3) noncoding ribonucleic acid: isoform structure, expression, and functions. Endocrinology 2010;151:939-947. 


\section{Cellular Physiology Cell Physiol Biochem 2017;44:447-454

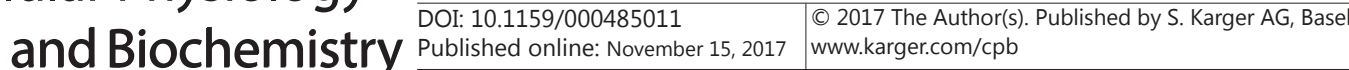

Li et al.:HOTAIR SNP and Hepatocellular Carcinoma

8 Burd CE, Jeck WR, Liu Y, Sanoff HK, Wang Z, Sharpless NE: Expression of linear and novel circular forms of an INK4/ARF-associated non-coding RNA correlates with atherosclerosis risk. PLoS Genet 2010;6:e1001233.

-9 Chung S, Nakagawa H, Uemura M, Piao L, Ashikawa K, Hosono N, Takata R, Akamatsu S, Kawaguchi T, Morizono T, Tsunoda T, Daigo Y, Matsuda K, Kamatani N, Nakamura Y, Kubo M: Association of a novel long non-coding RNA in 8q24 with prostate cancer susceptibility. Cancer Sci 2011;102:245-252.

10 Han Y, Rand KA, Hazelett DJ, Ingles SA, Kittles RA, Strom SS, Rybicki BA, Nemesure B, Isaacs WB, Stanford JL, Zheng W, Schumacher FR, Berndt SI, Wang Z, Xu J, Rohland N, Reich D, Tandon A, Pasaniuc B, Allen A, et al: Prostate cancer susceptibility in men of African ancestry at 8q24. J Natl Cancer Inst 2016;108: doi: 10.1093/jnci/djv431.

11 Wu H, Shang X, Shi Y, Yang Z, Zhao J, Yang M, Li Y, Xu S: Genetic variants of lncRNA HOTAIR and risk of epithelial ovarian cancer among Chinese women. Oncotarget 2016; 7:41047-41052.

12 Li C, Chen J, Zhang K, Feng B, Wang R, Chen L: Progress and Prospects of Long Noncoding RNAs (lncRNAs) in Hepatocellular Carcinoma. Cell Physiol Biochem 2015;36:423-434.

-13 Wang PY, Li JH, Liu YM, Lv Q, Xie N, Zhang HH, Xie SY: Single nucleotide polymorphisms in ZNRD1-AS1 increase cancer risk in an Asian population. Oncotarget 2017;8:10064-10070.

14 Verhaegh GW, Verkleij L, Vermeulen SH, den Heijer M, Witjes JA, Kiemeney LA: Polymorphisms in the H19 gene and the risk of bladder cancer. Eur Urol 2008;54:1118-1126.

15 Cai B, Song XQ Cai JP, Zhang S: HOTAIR: a cancer-related long non-coding RNA. Neoplasma 2014;61:379391.

-16 Xu CZ, Jiang C, Wu Q Liu L, Yan X, Shi R: A Feed-Forward Regulatory Loop between HuR and the Long Noncoding RNA HOTAIR Promotes Head and Neck Squamous Cell Carcinoma Progression and Metastasis. Cell Physiol Biochem 2016;40:1039-1051.

17 Gupta RA, Shah N, Wang KC, Kim J, Horlings HM, Wong DJ, Tsai MC, Hung T, Argani P, Rinn JL, Wang Y, Brzoska P, Kong B, Li R, West RB, van de Vijver MJ, Sukumar S, Chang HY: Long non-coding RNA HOTAIR reprograms chromatin state to promote cancer metastasis. Nature 2010;464:1071-1076.

-18 Zhu H, Lv Z, An C, Shi M, Pan W, Zhou L, Yang W, Yang M: Onco-lncRNA HOTAIR and its functional genetic variants in papillary thyroid carcinoma. Sci Rep 2016;6:31969.

19 Guo L, Lu X, Zheng L, Liu X, Hu M: Association of Long Non-Coding RNA HOTAIR Polymorphisms with Cervical Cancer Risk in a Chinese Population. PLoS One 2016;11:e0160039.

20 Zhang X, Zhou L, Fu G, Sun F, Shi J, Wei J, Lu C, Zhou C, Yuan Q Yang M: The identification of an ESCC susceptibility SNP rs 920778 that regulates the expression of IncRNA HOTAIR via a novel intronic enhancer. Carcinogenesis 2014;35:2062-2067.

21 Xue Y, Gu D, Ma G, Zhu L, Hua Q, Chu H, Tong N, Chen J, Zhang Z, Wang M: Genetic variants in IncRNA HOTAIR are associated with risk of colorectal cancer. Mutagenesis 2015;30:303-310.

-22 Bhan A, Hussain I, Ansari KI, Kasiri S, Bashyal A, Mandal SS: Antisense transcript long noncoding RNA (lncRNA) HOTAIR is transcriptionally induced by estradiol. J Mol Biol 2013;425:3707-3722.

-23 Bhan A, Mandal SS: LncRNA HOTAIR: A master regulator of chromatin dynamics and cancer. Biochim Biophys Acta 2015;1856:151-164.

24 Chen J, Lin C, Yong W, Ye Y, Huang Z: Calycosin and genistein induce apoptosis by inactivation of HOTAIR/pAkt signaling pathway in human breast cancer MCF-7 cells. Cell Physiol Biochem 2015;35:722-728.

25 Lv XB, Lian GY, Wang HR, Song E, Yao H, Wang MH: Long noncoding RNA HOTAIR is a prognostic marker for esophageal squamous cell carcinoma progression and survival. PLoS One 2013;8:e63516.

-26 Cai B, Wu Z, Liao K, Zhang S: Long noncoding RNA HOTAIR can serve as a common molecular marker for lymph node metastasis: a meta-analysis. Tumour Biol 2014;35:8445-8450.

27 He BS, Sun HL, Xu T, Pan YQ, Lin K, Gao TY, Zhang ZY, Wang SK: Association of genetic polymorphisms in the LncRNAs with gastric cancer risk in a Chinese population. J Cancer 2017;8:531-536.

28 Guo W, Dong Z, Bai Y, Guo Y, Shen S, Kuang G, Xu J: Associations between polymorphisms of HOTAIR and risk of gastric cardia adenocarcinoma in a population of north China. Tumour Biol 2015;36:2845-2854.

29 Ulger Y, Dadas E, Yalinbas Kaya B, Sumbul AT, Genc A, Bayram S: The analysis of lncRNA HOTAIR rs12826786 C > T polymorphism and gastric cancer susceptibility in a Turkish population: lack of any association in a hospital-based case-control study. Ir J Med Sci 2017.

-30 Bayram S, Ulger Y, Sumbul AT, Kaya BY, Rencuzogullari A, Genc A, Sevgiler Y, Bozkurt O, Rencuzogullari E: A functional HOTAIR rs920778 polymorphism does not contributes to gastric cancer in a Turkish population: a case-control study. Fam Cancer 2015;14:561-567.

31 Bayram S, Sumbul AT, Batmaci CY, Genc A: Effect of HOTAIR rs920778 polymorphism on breast cancer susceptibility and clinicopathologic features in a Turkish population. Tumour Biol 2015;36:3863-3870. 